\title{
Impact of Hypoxia on Early Chick Embryo Growth and Cardiovascular Function
}

\author{
SUMEET K. SHARMA, JENNIFER L. LUCITTI, CORY NORDMAN, JOSEPH P. TINNEY, KIMIMASA TOBITA, AND \\ BRADLEY B. KELLER
}

\author{
Department of Pediatrics [S.K.S., J.L.L., J.P.T., K.T., B.B.K.], Department of Physiology and Cell Biology [B.B.K.], Children's Hospital of \\ Pittsburgh, Pittsburgh, Pennsylvania 15213; The University of Pittsburgh School of Medicine [C.N.] , Pittsburgh, Pennsylvania 15213
}

\begin{abstract}
Oxygen tension is a critical factor for appropriate embryonic and fetal development. Chronic hypoxia exposure alters cardiovascular $(\mathrm{CV})$ function and structure in the late fetus and newborn, yet the immature myocardium is considered to be less sensitive to hypoxia than the mature heart. We tested the hypothesis that hypoxia during the period of primary $\mathrm{CV}$ morphogenesis impairs immature embryonic $\mathrm{CV}$ function and embryo growth. We incubated fertile white Leghorn chick embryos in $15 \%$ oxygen (hypoxia) or $21 \%$ oxygen (control) until Hamburger-Hamilton stage 21 (3.5 d). We assessed in ovo viability and dysmorphic features and then measured ventricular pressure and dimensions and dorsal aortic arterial impedance at stage 21. Chronic hypoxia decreased viability and embryonic wet weight. Chronic hypoxia did not alter heart rate or the ventricular diastolic indices of end-diastolic pressure, maximum ventricular $-\mathrm{dP} / \mathrm{dt}$, or tau. Chronic hypoxia decreased maximum ventricular $+\mathrm{dP} / \mathrm{dt}$ and peak pressure, increased ventricular end-systolic volume, and decreased ventricular ejection fraction, consistent with depressed systolic function. Arterial afterload (peripheral resistance) increased and both dorsal aortic SV and steady-state hydraulic power decreased in response to hypoxia. Thus, reduced oxygen tension during early cardiac development depresses ventricular function, increases ventricular impedance (afterload), delays growth, and decreases embryo survival, suggesting that a critical threshold of oxygen tension is required to support morphogenesis and cardiovascular function in the early embryo. (Pediatr Res 59: 116-120, 2006)
\end{abstract}

$\mathrm{O}$ xygen tension is a critical determinant of appropriate embryonic and fetal development (1-7), and hypoxia is associated with increased fetal mortality. Specifically, hypoxia is known to cause decreased birth weight, cerebrovascular anomalies, CV dysfunction, and altered angiogenesis (2-6), with hypoxia producing greater negative effects later in gestation (7). Reduced oxygen tension at higher altitude alters CV function, reduces fetal growth, and increases fetal demise (8). Variations in oxygen tension during development due to maternal cyanotic congenital heart disease also increase fetal loss and growth restriction (9). Although it is clear that reduced oxygen tension impacts fetal growth and survival, there are limited data on the role of hypoxia in directly regulating embryonic $\mathrm{CV}$ growth and function during the period of primary cardiac morphogenesis.

Received April 27, 2005; accepted June 29, 2005.

Correspondence: Bradley B. Keller, M.D., Chief, Division of Cardiology, 3705 Fifth Ave., Pittsburgh, PA 15213; e-mail: Bradley.Keller@hp.edu

This project was supported by National Institutes of Health grants NHLBI 1-RO1HL64626 (B.K.) and 1-RO1HL65219 (B.K) and by the Children's Hospital of Pittsburgh Foundation.

DOI: $10.1203 / 01 . p d r .0000191579 .63339 .90$
Vertebrate embryos that develop in ovo provide excellent experimental models to investigate the relationship between oxygen tension, $\mathrm{CV}$ performance, growth, and morphogenesis. The chick embryo has become the standard in ovo experimental model for physiologic assessment because of the ability to quantify embryonic CV function during normal development and in response to physiologic, pharmacologic, mechanical, and environmental challenges. For example, the developing embryonic $\mathrm{CV}$ system can respond to acute changes in ventricular preload and afterload $(10,11)$ as well as chronic changes in loading conditions $(12,13)$. Acute hypoxia produces a dose-dependent depression in embryonic chick ventricular contractility (14) and the embryonic myocardium displays the ability to survive acute anoxia-reoxygenation with reduced apoptosis versus the mature heart $(15,16)$. Chronic hypoxia late in gestation (d 19) is associated with cardiac contractile dysfunction, ventricular hypertrophy, and aortic intimal hypertrophy (3). In general, hypoxia in embryos and larvae reduces the rate of development and retards growth, however, a variety of vertebrate species adapted to low oxygen tension environments can develop normally in hypoxic conditions (17).

The early embryo relies on direct diffusion for environmental oxygen and nutrients (17). After $4 \mathrm{~d}$ of incubation, the embryonic chick reaches a critical mass that requires cardiac function and intravascular blood flow for nutrient delivery (17). Of note, cardiac output is initially disproportionately distributed to extraembryonic vessels early in development and the proportion of cardiac output distributed to the embryo increases commensurate with increasing metabolic demand $(18,19)$. During the second half of gestation, compensatory mechanisms such as activation of the autonomic nervous system and catecholamine release redistribute cardiac output to the heart and brain in response to hypoxia $(19,20)$.

Most studies of the detrimental effects of hypoxia on CV morphogenesis and function have focused on late gestation $(6,19,20)$. The current study was designed to investigate the $\mathrm{CV}$ response to hypoxia during early embryogenesis and to test the hypothesis that hypoxia alters both embryonic ven-

Abbreviations: CV, cardiovascular; EDA, end-diastolic area; EDP, enddiastolic pressure; HR, heart rate; PSP, peak-systolic pressure; SV, stroke volume 
tricular and vascular function in the early embryo. We measured embryo viability and both ventricular and vascular function in chick embryos incubated to stage 21 in either $21 \%$ or $15 \%$ fraction of inspired oxygen $\left(\mathrm{FiO}_{2}\right)$.

\section{METHODS}

Embryo preparation. Fertile White Leghorn chicken eggs were obtained from Utah State University (Logan, UT). Eggs were incubated blunt side up in air-tight chambers maintained at an oxygen level of either 15\% (hypoxia) or $21 \%$ (control) and air was replaced daily. Chambers were placed within an incubator maintained at $38^{\circ} \mathrm{C}$ and $60-70 \%$ humidity. Embryos were incubated to Hamburger-Hamilton (21) stage 21 of 46 stages ( $3.5 \mathrm{~d}$ of gestation, 21-d incubation period). The numbers of embryos included in each group are listed in Tables 1-3. Our research protocols conform to the Guide for the Care and Use of Laboratory Animals (National Institutes of Health Publication No. 85-23, Revised 1985) and our use of chick embryos has been approved by the Children's Hospital of Pittsburgh Animal Care Committee.

Morphometry. Individual eggs were placed in a temperature-controlled environment, and the embryo was exposed by creating a window in the shell above the air cell and resecting the membranes above the embryo. Embryos were assessed for dysmorphic features in ovo using a photomicroscope (Model SZH10, Olympus, Tokyo, Japan) and then sequential video images of developing embryo were acquired using a videocamera (Model KP-M1U, Hitachi Denshi, Ltd., Yokohama, Japan), frame-grabber board (LG-3, Scion, Frederick, MD), and public domain National Institutes of Health-Image software (version 1.63). We defined a "viable" embryo as alive and nondysmorphic, and thus eligible for physiologic investigation. We measured retinal cross-sectional area and CRL in situ from individual embryos. We then excised the embryo by severing the vitelline veins and arteries where they exited the embryo and removed all extraembryonic membranes. Embryos were lightly blotted on filter paper and weighed (22).

Ventricular pressure. All pressure measurements were performed in ovo and all data were recorded within $5 \mathrm{~min}$ of egg removal from the incubator. Embryo temperature was maintained at $38^{\circ} \mathrm{C}$ by ambient warming with intermittent measurement of embryo temperature using a thermistor. A fluidfilled glass capillary pipette was positioned using a micromanipulator (Leitz, Wetzlar, Germany) to puncture the developing ventricle and measure intraventricular pressure using a servo-null pressure system (model 900A, World Precision Instruments, Sarasota, FL). The servo-null pressure is linear $(y=$ $0.995 x-0.23, r=0.99, \mathrm{SE}=0.11 \mathrm{~mm} \mathrm{Hg}$ ) to a standing water column over the range of $0-30 \mathrm{~mm} \mathrm{Hg}$ (22). Pressure signals were captured at $600 \mathrm{~Hz}$ with an analog-digital board (AT-MIO 16; National Instruments, Austin, TX) and custom-programmed data acquisition system (LabVIEW, National Instruments,). Sequential video images of the contracting embryonic heart were captured at 60 fields per second for $4 \mathrm{~s}$.

Arterial hemodynamics. We measured simultaneous dorsal aortic blood pressure with the servo-null system (model 900A, World Precision Instruments) and dorsal aortic blood velocity with a pulsed-Doppler velocimeter (Triton, San Diego, CA) and a 0.5-mm custom-mounted piezoelectric crystal (Iowa Doppler Products, Iowa City, IA) at the level of the sinus venosus (10). Dorsal aortic diameter was imaged for individual embryos using a video camera (model 70, Dage-MTI, Michigan City, IN) mounted on a photomacroscope. We calibrated the image analysis software (Scion Image, Scion) using a 50- $\mu \mathrm{m}$-division scribed glass standard was recorded in the plane of each embryo for measurement software calibration. Diameters were determined at two magnifications, compared with each other to verify accuracy, and then averaged to yield one dorsal aortic diameter at the level of the sinus venosus per embryo. After correction for the Doppler probe angle, dorsal aortic SV was calculated as the product of the area under the curve of flow velocity for a single cardiac cycle and dorsal aortic cross sectional area.

Intraventricular pressure. Intraventricular pressure was calculated as the difference between the measured pressure and pressure recorded when the

Table 1. Survival and morphometrics for control $\left(21 \% \mathrm{FiO}_{2}\right)$ and hypoxic embryos $\left(15 \% \mathrm{FiO}_{2}\right)$

\begin{tabular}{lclclll}
\hline & & & & & $p$ \\
& \multicolumn{2}{c}{$21 \% \mathrm{FiO}_{2}$} & \multicolumn{2}{c}{$15 \% \mathrm{FiO}_{2}$} & \multicolumn{1}{c}{$\begin{array}{c}p \\
\text { Value }\end{array}$} \\
\hline Survival & $77 \%$ & $(n=569)$ & $64 \% *$ & $(n=555)$ & 0.001 \\
Wet weight $(\mathrm{mg})$ & $38 \pm 2$ & $(n=19)$ & $33 \pm 1^{*}$ & $(n=23)$ & 0.03 \\
Retinal area $\left(\mathrm{mm}^{2}\right)$ & $0.66 \pm 0.03$ & $(n=23)$ & $0.61 \pm 0.03$ & $(n=23)$ & 0.29 \\
CRL (mm) & $5.98 \pm 0.10$ & $(n=22)$ & $5.87 \pm 0.11$ & $(n=23)$ & 0.46 \\
\hline
\end{tabular}

Data are presented as mean \pm SEM. CRL, crown-rump length. $* p<0.05$. glass capillary tip was placed in extraembryonic fluid adjacent to the embryo. Pressure waveforms were analyzed to determine heart rate (HR, bpm), peak systolic pressure (PSP, $\mathrm{mm} \mathrm{Hg}), \mathrm{EDP}(\mathrm{mm} \mathrm{Hg}), \mathrm{dP} / \mathrm{dt}$, and time constant of ventricular pressure decay (tau). Three consecutive ventricular pressure waveforms were used to calculate HR. The PSP was determined as the point of maximum intraventricular pressure and EDP was defined as the point immediately before the onset of ventricular systole. The maximum positive and negative first-derivatives of ventricular pressure were calculated electronically. All calculations were performed using a custom-made data analysis program (LabVIEW, National Instruments).

Video image processing. We planimetered the ventricular epicardial border manually from each video field for three sequential cardiac cycles to determine epicardial ventricular cross-sectional area (A). EDA and ESA was then defined at maximum and minimum areas. Fractional area change (FAC) was calculated as $100 \times(\mathrm{EDA}-\mathrm{ESA}) / \mathrm{EDA}$. Intra- and interobserver error of area measurement by planimetry is not significant $(p=0.29$ and $p=0.96$, respectively) (23)

Arterial hemodynamics. Input impedance spectra were generated as previously described $(10,24)$. We defined total vascular resistance (TVR) as the impedance modulus at $0 \mathrm{~Hz},\left(\mathrm{Z}_{1}\right)$ as the impedance modulus at the first harmonic, characteristic impedance $\left(Z_{C}\right)$ as the average of the impedance moduli from the third harmonic up to $10 \mathrm{~Hz}$ and peripheral impedance $\left(Z_{\mathrm{P}}\right)$ as the difference between TVR and $Z_{C}$. Total arterial compliance $\left(C_{A}\right)$ was calculated using the area under the pressure wave form:

$$
\mathrm{C}_{\mathrm{A}}=\mathrm{SV} /\left[\left(\left(\mathrm{A}_{\mathrm{S}}+\mathrm{A}_{\mathrm{D}}\right) / \mathrm{A}_{\mathrm{D}}\right) \cdot\left(\mathrm{P}_{\mathrm{N}}-\mathrm{P}_{\mathrm{D}}\right)\right]
$$

where SV is stroke volume, $\mathrm{P}_{\mathrm{N}}$ and $\mathrm{P}_{\mathrm{D}}$ are dicrotic notch and end diastole pressures, respectively, and $A_{S}$ and $A_{D}$ are the areas under the aortic pressure wave form during systole and diastole, respectively.

Steady Power $\left(\mathrm{W}_{\mathrm{S}}\right)$ was calculated as:

$$
\mathrm{W}_{\mathrm{S}}=\mathrm{P}_{\mathrm{M}} \cdot \mathrm{Q}_{\mathrm{M}}
$$

where $\mathrm{P}_{\mathrm{M}}$ and $\mathrm{Q}_{\mathrm{M}}$ are mean pressure and flow, respectively. Oscillatory power $\left(\mathrm{W}_{\mathrm{O}}\right)$ was calculated as:

$$
\mathrm{W}_{\mathrm{O}}=(1 / 2) \Sigma\left(\left|\mathrm{Q}_{\mathrm{n}}\right|\right)(2) \cdot\left|\mathrm{Z}_{\mathrm{n}}\right| \cdot \cos \theta_{\mathrm{n}}
$$

where $\left|\mathrm{Q}_{\mathrm{n}}\right|,\left|\mathrm{Z}_{\mathrm{n}}\right|$, and $\theta_{\mathrm{n}}$ are the flow modulus, the impedance modulus, and the impedance phase angle at the nth harmonic. Oscillatory fraction of hydraulic power is:

$$
\% \mathrm{~W}_{\mathrm{O}}=\left[\mathrm{W}_{\mathrm{O}} /\left(\mathrm{W}_{\mathrm{S}}+\mathrm{W}_{\mathrm{O}}\right)\right] \cdot 100
$$

Total power $\left(\mathrm{W}_{\mathrm{T}}\right)$ was calculated as:

$$
\mathrm{W}_{\mathrm{T}}=\mathrm{W}_{\mathrm{S}}+\mathrm{W}_{\mathrm{O}}
$$

Statistical analysis. Data are reported as means \pm SEM. Independent $t$ tests and $\chi^{2}$ analysis were performed to compare the mean values between control and hypoxia groups. Statistical significance was determined at a level of $5 \%$ alpha error between groups for each measure $(p<0.05)$. Ventricular statistical analyses were performed using SigmaStat (Systat Software Inc, Point Richmond, CA) and hemodynamic analyses were performed using SPSS (Jandel Scientific, Costa Madre, CA).

\section{RESULTS}

Global impact of hypoxia. Table 1 summarizes the survival and morphologic data for control embryos and for embryos incubated at $15 \% \mathrm{Fio}_{2}$ to stage 21 . Chronic hypoxia at $15 \%$ $\mathrm{FiO}_{2}$ reduced embryo survival versus controls (Table 1). There was no difference between the rates of infertile eggs (3\% versus $5 \%$ ) or dysmorphic embryos (12\% versus $9 \%$ ) for eggs incubated to stage 21 in $15 \%$ versus $21 \% \mathrm{Fio}_{2}$. We noted a decrease in embryo wet weight but no change in retinal cross-sectional area or crown-rump length in hypoxic embryos versus controls, respectively (Table 1 ).

Ventricular function. Table 2 and Figure 1 summarize ventricular function in control embryos and in embryos exposed to $15 \% \mathrm{FiO}_{2}$ until stage 21 . We noted no change in HR in hypoxic embryos versus controls. Of note, hypoxia reduced measures of systolic performance including PSP, maximum $+\mathrm{dP} / \mathrm{dt}$, and FAC. Hypoxia did not reduce measures of dia- 
Table 2. Ventricular function in control $\left(21 \% \mathrm{FiO}_{2}\right)$ and hypoxic embryos $\left(15 \% \mathrm{FiO}_{2}\right)$

\begin{tabular}{|c|c|c|c|c|c|}
\hline \multirow[b]{2}{*}{ HR (bpm) } & \multicolumn{2}{|c|}{$21 \% \mathrm{FiO}_{2}$} & \multicolumn{2}{|c|}{$15 \% \mathrm{FiO}_{2}$} & \multirow{2}{*}{$\frac{p \text { Value }}{0.300}$} \\
\hline & $150 \pm 3$ & $(n=37)$ & $146 \pm 2$ & $(n=33)$ & \\
\hline $\operatorname{ESA}\left(\mathrm{mm}^{2}\right)$ & $0.60 \pm 0.02$ & $(n=17)$ & $0.73 \pm 0.03 *$ & $(n=23)$ & 0.008 \\
\hline $\operatorname{EDA}\left(\mathrm{mm}^{2}\right)$ & $0.83 \pm 0.04$ & $(n=17)$ & $0.94 \pm 0.04$ & $(n=23)$ & 0.130 \\
\hline PSP (mm Hg) & $2.15 \pm 0.04$ & $(n=37)$ & $1.95 \pm 0.06^{*}$ & $(n=33)$ & 0.005 \\
\hline$+\mathrm{dP} \mathrm{dt}_{\max }(\mathrm{mm} \mathrm{Hg} / \mathrm{s})$ & $68.1 \pm 3.2$ & $(n=37)$ & $57.9 \pm 3.2 *$ & $(n=33)$ & 0.030 \\
\hline$-\mathrm{dP} / \mathrm{dt}_{\max }(\mathrm{mm} \mathrm{Hg} / \mathrm{s})$ & $-53.3 \pm 5.4$ & $(n=37)$ & $-52.6 \pm 3.2$ & $(n=33)$ & 0.900 \\
\hline
\end{tabular}

Data are presented as mean \pm SEM. ESA, end systolic area; FAC, fractional area change; $\mathrm{dP}_{\mathrm{dt}}{ }_{\max }$, maximum pressure change per second.

Table 3. Arterial function in control embryos $\left(21 \% \mathrm{Fio}_{2}\right)$ and hypoxic embryos $\left(15 \% \mathrm{FiO}_{2}\right)$

\begin{tabular}{lccc}
\hline & $\begin{array}{c}\mathrm{FiO}_{2} 21 \% \\
(n=11)\end{array}$ & $\begin{array}{c}\mathrm{FiO}_{2} 15 \% \\
(n=14)\end{array}$ & $p$ Value \\
\hline $\mathrm{SV}(\mu \mathrm{L})$ & $0.30 \pm 0.01$ & $0.25 \pm 0.02^{*}$ & 0.026 \\
Compliance $(\mu \mathrm{L} / \mathrm{mm} \mathrm{Hg})$ & $0.11 \pm 0.02$ & $0.08 \pm 0.02$ & 0.200 \\
Ao DP $(\mathrm{mm} \mathrm{Hg})$ & $0.56 \pm 0.03$ & $0.64 \pm 0.03$ & 0.070 \\
Ao SP $(\mathrm{mm} \mathrm{Hg})$ & $1.83 \pm 0.04$ & $1.68 \pm 0.05^{*}$ & 0.038 \\
$\mathrm{MAP}(\mathrm{mm} \mathrm{Hg})$ & $1.12 \pm 0.03$ & $1.10 \pm 0.03$ & 0.623 \\
$\mathrm{CO}(\mu \mathrm{L} / \mathrm{min})$ & $46.1 \pm 2.1$ & $38.4 \pm 2.4^{*}$ & 0.027 \\
$\mathrm{Mean} \mathrm{Q}(\mu \mathrm{L} / \mathrm{s})$ & $0.75 \pm 0.04$ & $0.62 \pm 0.04^{*}$ & 0.021 \\
$\mathrm{~W}_{\mathrm{T}}(\mathrm{mm} \mathrm{Hg} / \mu \mathrm{L} / \mathrm{s})$ & $1.19 \pm 0.09$ & $0.90 \pm 0.07^{*}$ & 0.015 \\
$\mathrm{~W}_{\mathrm{S}}(\mathrm{mm} \mathrm{Hg} / \mu \mathrm{L} / \mathrm{s})$ & $0.84 \pm 0.05$ & $0.68 \pm 0.05^{*}$ & 0.035 \\
$\mathrm{~W}_{\mathrm{O}}(\mathrm{mm} \mathrm{Hg} / \mu \mathrm{L} / \mathrm{s})$ & $0.35 \pm 0.05$ & $0.21 \pm 0.03^{*}$ & 0.016 \\
$\% \mathrm{~W}_{\mathrm{O}}$ & $28.4 \pm 1.8$ & $23.4 \pm 1.5^{*}$ & 0.037 \\
\hline
\end{tabular}

Data are presented as mean \pm SEM. SV, stroke volume; Ao DP, dorsal aortic diastolic pressure; Ao SP, dorsal aortic peak systolic pressure; MAP, mean arterial pressure; $\mathrm{CO}$, cardiac output; $\mathrm{Q}$, flow; $\mathrm{W}_{\mathrm{T}}$, total power; $\mathrm{W}_{\mathrm{S}}$, steady power; $\mathrm{W}_{\mathrm{O}}$, oscillatory power. $* p<0.05$.

stolic performance, including EDP $(p=0.820)$, maximum $-\mathrm{dP} / \mathrm{dt}$, or tau.

Ventricular afterload. Table 3 and Figure 2 summarize dorsal aortic hemodynamics and arterial impedance in control embryos and embryos exposed to $15 \% \mathrm{FiO}_{2}$ until stage 21 . Chronic hypoxia reduced dorsal aortic systolic pressure but not mean arterial pressure. Chronic hypoxia reduced SV, cardiac output, and mean dorsal aortic flow. Chronic hypoxia increased input impedance $\left(\mathrm{Z}_{\mathrm{I}}, 2.07 \pm 0.17\right.$ versus $1.58 \pm$ $0.13 \mathrm{~mm} \mathrm{Hg} / \mathrm{s} / \mu \mathrm{L}, p=0.040)$, and peripheral impedance $\left(Z_{\mathrm{P}}\right.$, $1.59 \pm 0.15$ versus $1.03 \pm 0.13 \mathrm{~mm} \mathrm{Hg} / \mathrm{s} / \mu \mathrm{L}, p=0.012)$, but not fundamental impedance $(p=0.407)$, characteristic impedance $(p=0.691)$, or arterial compliance $(p=0.203)$. Chronic hypoxia reduced total hydraulic power, steady hydraulic power, and oscillatory power. The percentage of oscillatory power also decreased in response to hypoxia.

\section{DISCUSSION}

Chronic hypoxia is well established to cause reduced growth and altered $\mathrm{CV}$ function in the mid- and late-gestation fetus $(3,5,8,25)$ with life-long consequences $(26)$. In the current study, we tested the hypothesis that hypoxia alters both embryonic ventricular and vascular function and growth in the early embryo during the critical period of early morphogenesis when changes in ventricular and arterial function can produce permanent structural and functional alterations $(12,13,24,27-$ 29). In response to chronic hypoxia from the onset of incubation, we noted decreased ventricular systolic function, increased arterial impedance, reduced arterial blood flow, and

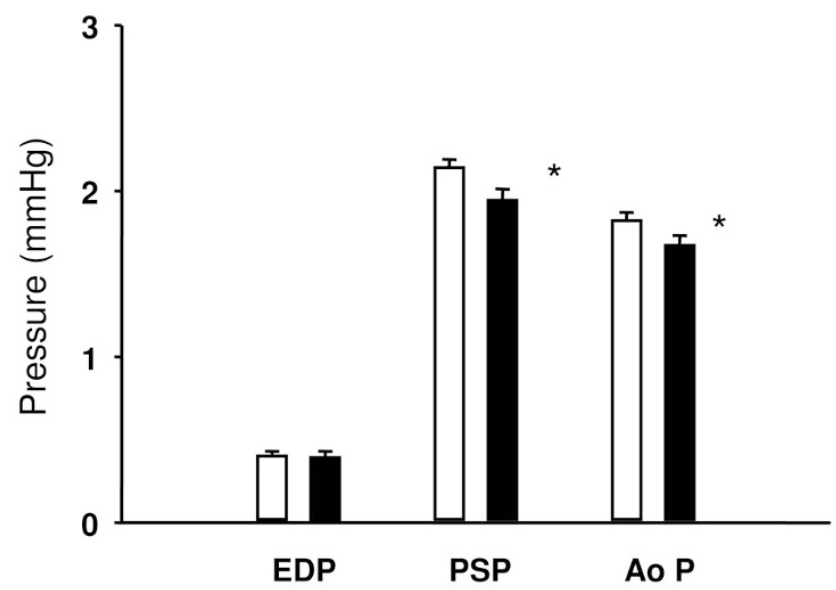

Figure 1. Ventricular pressure and dorsal aortic pressure in control embryos $\left(21 \% \mathrm{FiO}_{2}\right.$, open bars $)$ and hypoxic embryos $\left(15 \% \mathrm{Fio}_{2} ;\right.$ filled bars $) . \mathrm{EDP}$, ventricular end diastolic pressure $\left(n=37\right.$ and $n=33$, for $21 \%$ and $15 \% \mathrm{FiO}_{2}$, respectively); PSP, ventricular peak systolic pressure $(n=37$ and $n=33$, respectively for $21 \%$ and $15 \% \mathrm{FiO}_{2}$ ); Ao $\mathrm{P}$, dorsal aortic peak systolic pressure, ( $n=11$ and $n=14$, for $21 \%$ and $15 \% \mathrm{Fio}_{2}$, respectively). $* p<0.05$.

reduced embryo growth and survival. These observations support a working hypothesis that sublethal (and perhaps subclinical) hypoxia can impact CV function, structure, and fate during embryogenesis.

Effects of hypoxia on early embryo growth and survival. The initial effects of reduced oxygen availability on the developing embryo are likely due to direct effects on cellular metabolism and growth $(30,31)$. We found that embryo growth was affected by hypoxic conditions as early as stage 21 (d 3.5 of a 21-d gestation) with reduced embryo weight despite no change in CRL or retinal area. It is important to differentiate between the functional consequences of reduced nutrient availability (e.g. during hypoxia) and reduced cardiac function (e.g. during conotruncal constriction) in the early embryo. Numerous studies have described reduced growth with and without altered rate of developmental maturation in response to hypoxia $(2,5,6,20,32)$. Our finding of increased embryo mortality after hypoxia is consistent with the observation that a critical threshold of oxygen availability is required to initiate and sustain early embryo development. Changes in embryo growth at these early stages are likely not related to impaired cardiovascular function as early embryo growth can occur in the absence of cardiac function due to the direct diffusion of nutrients to the embryo $(17,33,34)$.

Heart rate independence. Our finding that chronic hypoxia did not alter embryo HR differs from the bradycardic 


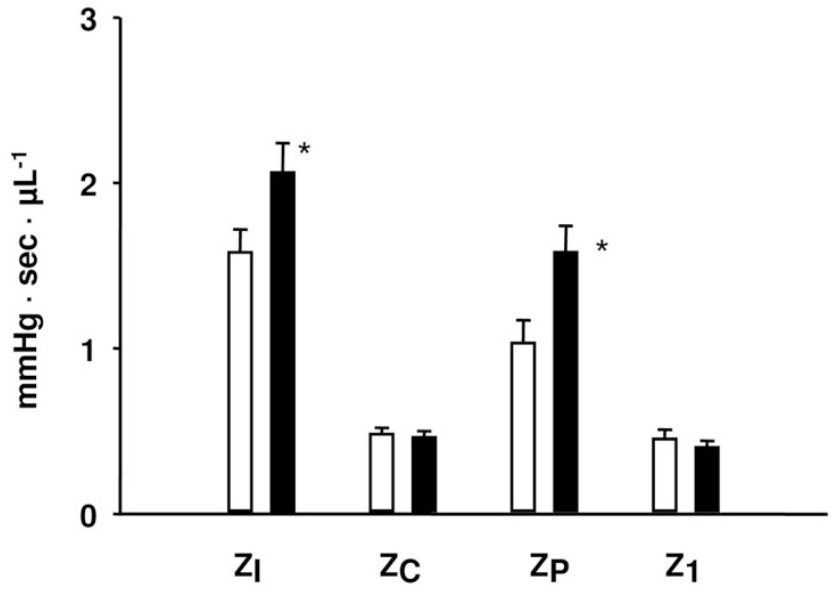

Figure 2. Arterial impedance in control embryos $\left(21 \% \mathrm{FiO}_{2}\right.$, open bars, $n=$ $11)$ and hypoxic embryos $\left(15 \% \mathrm{Fio}_{2}\right.$, filled bars, $\left.n=14\right)$. $\mathrm{Z}_{\mathrm{I}}$, input impedance; $Z c$, characteristic impedance; $Z_{P}$, peripheral impedance; $Z_{1}$, fundamental impedance. ${ }^{*} p<0.05$.

response to hypoxia noted in fetal and adult vertebrates and is consistent with published data in the early embryo $(10,13,14,18,24,28,35,36)$. In contrast to the mid- and lategestation fetus, the early embryo does not compensate for impaired CV function by adjusting HR. The embryonic myocardium does respond to exogenous catecholamines $(37,38)$ and adrenergic agents (39) due to surface receptors that are present before functional autonomic innervation (40) and functional catecholamine synthesis is required for embryo survival (41). Hypoxia produced by $10 \%$ oxygen reduces HR in the $\mathrm{d} 7$ chick embryo (42), even though the parasympathetic and sympathetic limbs of the autonomic nervous system are not functional in the chick embryo before d 12 and 20, respectively (40). Thus, hypoxia does not trigger HR compensation via baroreflex, chemoreceptor reflexes, or autonomic innervation in avian embryos until the last third of gestation $(20,40,43,44)$.

Effects of hypoxia on ventricular function. Depressed systolic function in response to chronic hypoxia in the early embryo is similar to findings in the mid- and late-gestation fetus $(3,14,19,45)$. Impaired systolic performance can result from either 1) primary contractile dysfunction, or 2) increased afterload resulting in compromised systolic ejection. In our current study, hypoxia decreased ventricular systolic parameters (decreased PSP, decreased $(+) \mathrm{dP} / \mathrm{dt}$, decreased fractional area shortening) despite preserved ventricular preload and diastolic function (EDA, EDP, tau). In the early chick embryo, an acute increase in afterload results in an increased ventricular systolic pressure (46) as does a chronic increase in afterload (12). Further studies are required to identify the underlying mechanism for hypoxia related contractile dysfunction at the level of energy substrate production and excitation-contraction coupling in developing myocardium.

It is important to note that diastolic function was not affected by hypoxia in the developing embryo. In the relatively low-pressure embryonic CV system, ventricular diastolic function includes a negative pressure at the end of isovolumic relaxation (11) and significant anisotropic untwisting (13) related to the unique geometry and material properties of the embryonic heart (29). Embryonic ventricular diastolic function is preserved in response to increased ventricular afterload produced by conotruncal banding $(12,47)$, but is impaired in response to reduced ventricular preload produced by left-atrial ligation $(47,48)$. Thus, whereas the maintenance of diastolic properties in developing myocardium requires a threshold of mechanical loading to stimulate myocardial growth and remodeling, myocardial architecture may be more resistant to variations in oxygen availability common to many invertebrates and vertebrate species (49).

Effects of hypoxia on vascular impedance. Hypoxia directly impairs endothelial cell function including the expression of vasoactive substances and matrix proteins involved in vascular tone (6). Our finding that chronic hypoxia increased ventricular afterload represented by input and peripheral impedance is consistent with dysregulated angiogenesis and the increase in arterial resistance noted following hypoxia in the fetus $(3,4,6,50)$. One paradox of developing CV systems is that the structurally and functionally immature embryonic myocardium is coupled to an immature vasculature with relatively high impedance versus the mature circulation (10). Vascular impedance decreases geometrically as the vasculature rapidly expands with a coincident geometric increase in systolic blood flow (10) and has been noted in normal pregnancies at high altitude (51). Increased vascular impedance in the early embryo is likely due to altered vascular growth and remodeling rather than increased arterial vascular smooth muscle "tone" at these early stages (24).

Molecular mechanisms for the embryonic response to hypoxia. Common molecular and metabolic pathways regulate the cellular response to hypoxia in diverse cell types and tissues. For example, the hypoxia inducible factor 1 alpha (HIF $1 \alpha$ ) pathway is involved in cellular adaptation to hypoxia and altered embryo growth through temporal, spatial, and tissue-specific adaptive responses $(3,52)$. HIF $1 \alpha$ is also required for normal cardiac morphogenesis (53). Hypoxiaresponsive signaling also regulates programmed cell death and remodeling in the embryonic chick outflow tract (54). We noted increased arterial resistance in hypoxic stage $21 \mathrm{em}-$ bryos consistent with reduced vasculogenesis and a delay in the normal fall in vascular resistance associated with development. In the mid- and late-gestation chick embryo hypoxia triggers a proportional increase in HIF $1 \alpha$ and angiogenesis (55). If hypoxia in the early chick embryo stimulates HIF $1 \alpha$ release, it would be reasonable to expect an altered vasculogenesis as noted later in development. However, if changes in vasculogenesis were not associated with increased branching or increase capillary networks then total vascular impedance might not decrease (4). Further work is required to correlate vascular branching patterns with arterial impedance at these early stages of embryogenesis. Of course, other mediators of vasculogenesis (nuclear factor of activated $\mathrm{T}$ cells, vascular endothelial growth factor, etc.) may also be targets regulated by oxygen tension during development (52).

Our data are consistent with studies throughout embryogenesis that confirm chronic hypoxia impairs CV function, embryo growth, and embryo survival, producing "altered developmental trajectories" $(49,55)$. Our data demonstrate that the functional 
adaptation of both the embryonic ventricle and vascular bed are negatively impacted by hypoxia during the critical period of cardiac morphogenesis. Further experiments to quantitate morphologic changes in ventricular and vascular architecture as well as the identification of hypoxia-sensitive genes and proteins regulated by the HIF $1 \alpha$ pathway are clearly needed. Finally, experiments with initial hypoxic incubation followed by the normoxia for the remainder of incubation will allow us to determine whether hypoxia induced "altered trajectories" are reversible or irreversible. These data in avian embryos will provide insight into early embryonic hypoxic adaptation in higher vertebrates, including humans.

\section{REFERENCES}

1. Jaffee OC 1974 The effects of moderate hypoxia and moderate hypoxia plus hypercapnea on cardiac development in chick embryos. Teratology 10:275-281

2. Meuer HJ, Hartmann V, Jopp S 1992 Tissue PO2 and growth rate in early chick embryos. Respir Physiol 90:227-237

3. Rouwet EV, Tintu AN, Schellings MW, van Bilsen, M, Lutgens E, Hofstra L, Slaaf DW, Ramsay G, Le Noble, FA 2002 Hypoxia induces aortic hypertrophic growth, left ventricular dysfunction, and sympathetic hyperinnervation of peripheral arteries in the chick embryo. Circulation 105:2791-2796

4. Strick DM, Waycaster RL, Montani JP, Gay WJ, Adair TH 1991 Morphometric measurements of chorioallantoic membrane vascularity: effects of hypoxia and hyperoxia. Am J Physiol 260:H1385-H1389

5. Miller SL, Green LR, Peebles DM, Hanson MA, Blanco CE 2002 Effects of chronic hypoxia and protein malnutrition on growth in the developing chick. Am J Obstet Gynecol 186:261-267

6. Villamor E, Kessels CG, Ruijtenbeek K, van Suylen, RJ, Belik J, de Mey, JG, Blanco CE 2004 Chronic in ovo hypoxia decreases pulmonary arterial contractile reactivity and induces biventricular cardiac enlargement in the chicken embryo. Am J Physiol Regul Integr Comp Physiol 287:R642-R651

7. Chan T, Burggren W 2005 Hypoxic incubation creates differential morphological effects during specific developmental critical windows in the embryo of the chicken (Gallus gallus). Respir Physiol Neurobiol 145:251-263

8. Thompson LP 2003 Effects of chronic hypoxia on fetal coronary response. High Alt Med Biol 4:215-224

9. Merchiers EH, Dhont M, De Sutter, PA, Beghin CJ, Vandekerckhove DA 1991 Predictive value of early embryonic cardiac activity for pregnancy outcome. Am J Obstet Gynecol 165:11-14

10. Yoshigi M, Hu N, Keller BB 1996 Dorsal aortic impedance in the stage 24 chick embryo following acute changes in circulating blood volume. Am J Physiol 270:H1597-H1606

11. Keller BB 1997 Embryonic cardiovascular function, coupling, and maturation: a species view. In: Burggren W, Keller BB (eds) Development of Cardiovascular Systems: Molecules to Organisms. Cambridge University Press, New York, pp 65-87

12. Clark EB, Hu N, Frommelt P, Vandekieft GK, Dummett JL, Tomanek RJ 1989 Effect of increased pressure on ventricular growth in stage 21 chick embryos. Am J Physiol 257:H55-H61

13. Tobita K, Keller BB 2000 Right and left ventricular wall deformation patterns in normal and left heart hypoplasia chick embryos. Am J Physiol Heart Circ Physiol 279:H959-H969

14. Ruckman RN, Rosenquist GC, Rademaker DA, Morse DE, Getson PR 1985 The effect of graded hypoxia on the embryonic chick heart. Teratology 32:463-472

15. Sedmera D, Kucera P, Raddatz E 2002 Developmental changes in cardiac recovery from anoxia-reoxygenation. Am J Physiol Regul Integr Comp Physiol 283:R379-R388

16. Sarre A, Lange N, Kucera P, Raddatz E 2005 mitoKATP channel activation in the postanoxic developing heart protects E-C coupling via NO-, ROS-, and PKCdependent pathways. Am J Physiol Heart Circ Physiol 288:H1611-H1619

17. Burggren WW, Warburton SJ, Slivkoff MD 2000 Interruption of cardiac output does not affect short- term growth and metabolic rate in day 3 and 4 chick embryos. J Exp Biol 203:3831-3838

18. van Golde J, Mulder T, Blanco CE 1997 Changes in mean chorioallantoic artery blood flow and heart rate produced by hypoxia in the developing chick embryo. Pediatr Res 42:293-298

19. Mulder AL, van Golde, JC, Prinzen FW, Blanco CE 1998 Cardiac output distribution in response to hypoxia in the chick embryo in the second half of the incubation time. J Physiol 508:281-287

20. Mulder AL, Miedema A, De Mey, JG, Giussani DA, Blanco CE 2002 Sympathetic control of the cardiovascular response to acute hypoxemia in the chick embryo. Am J Physiol Regul Integr Comp Physiol 282:R1156-R1163

21. Hamburger V, Hamilton HL 1951 A series of normal stages in the development of the chick embryo. J Morphol 88:49-92

22. Clark EB, Hu N 1982 Developmental hemodynamic changes in the chick embryo from state 18 to 27 . Circ Res 51:810-815

23. Keller BB, Hu N, Clark EB 1990 Correlation of ventricular area, perimeter, and conotruncal diameter with ventricular mass and function in the stage 12 to 24 chick embryo. Circ Res 66:109-114

24. Lucitti JL, Tobita K, Keller BB 2005 Arterial hemodynamics and mechanical properties after circulatory intervention in the chick embryo. J Exp Biol 208:1877-1885
25. Severi FM, Rizzo G, Bocchi C, D’Antona, D, Verzuri MS, Arduini, D 2000 Intrauterine growth retardation and fetal cardiac function. Fetal Diagn Ther 15:8-19 26. Barker DJ 1999 Fetal origins of cardiovascular disease. Ann Med 31:3-6

27. Sedmera D, Pexieder T, Rychterova V, Hu N, Clark EB 1999 Remodeling of chick embryonic ventricular myoarchitecture under experimentally changed loading conditions. Anat Rec 254:238-252

28. Stekelenburg-de Vos S, Ursem NT, Hop WC, Wladimiroff JW, Gittenberger-de Groot AC, Poelmann RE 2003 Acutely altered hemodynamics following venous obstruction in the early chick embryo. J Exp Biol 206:1051-1057

29. Tobita K, Garrison JB, Liu LJ, Tinney JP, Keller BB 2005 Three-dimensional myofiber architecture of the embryonic left ventricle during normal and development and altered mechanical loads. Anat Rec A Discov Mol Cell Evol Biol 283:193-201

30. Budinger GR, Chandel N, Shao ZH, Li CQ, Melmed A, Becker LB, Schumacker PT 1996 Cellular energy utilization and supply during hypoxia in embryonic cardiac myocytes. Am J Physiol 270:L44-L53

31. Bae S, Xiao Y, Li G, Casiano CA, Zhang L 2003 Effect of maternal chronic hypoxic exposure during gestation on apoptosis in fetal rat heart. Am J Physiol Heart Circ Physiol 285:H983-H990

32. Altimiras J, Phu L 2000 Lack of physiologic plasticity in the early chicken embryo exposed to acute hypoxia. J Exp Zool 286:450-456

33. Manasek FJ, Monroe RG 1972 Early cardiac morphogenesis is independent of function. Dev Biol 27:584-588

34. Pelster B, Burggren WW 1996 Disruption of hemoglobin oxygen transport does not impact oxygen-dependent physiological processes in developing embryos of zebra fish (Dania rerio). Circ Res 79:358-362

35. Keller BB, Hu N, Tinney JP 1994 Embryonic ventricular diastolic and systolic pressure-volume relation. Cardiol Young 4:19-27

36. Akiyama R, Mitsubayashi H, Tazawa H, Burggren WW 1999 Heart rate responses to altered ambient oxygen in early (days 3-9) chick embryos in the intact egg. J Comp Physiol B 169:85-92

37. Girard H 1973 Adrenergic sensitivity of circulation in the chick embryo. Am J Physiol 224:461-469

38. Clark EB, Hu N, Dooley JB 1985 The effect of isoproterenol on cardiovascular function in the stage 24 chick embryo. Teratology 31:41-47

39. Hofman PL, Hiatt K, Yoder MC, Rivkees SA 1997 A1 adenosine receptors potently regulate heart rate in mammalian embryos. Am J Physiol 273:R1374-R1380

40. Sanchez-Montesinos I, Merida-Velasco JA, Espin-Ferra J, Scopsi L 1996 Development of the sympathoadrenal system in the chick embryo: an immunocytochemical study with antibodies to pan-neuroendocrine markers, catecholamine-synthesizing enzymes, proprotein-processing enzymes, and neuropeptides. Anat Rec 245:94-101

41. Kobayashi K, Morita S, Sawada H, Mizuguchi T, Yamada K, Nagatsu I, Hata T, Watanabe Y, Fujita K, Nagatsu T 1995 Targeted disruption of the tyrosine hydroxylase locus results in severe catecholamine depletion and perinatal lethality in mice. J Biol Chem 270:27235-27243

42. Tazawa $\mathrm{H} 1981$ Effect of $\mathrm{O}_{2}$ and $\mathrm{CO}_{2}$ in $\mathrm{N}_{2}, \mathrm{He}$ and $\mathrm{SF}_{6}$ on chick embryo blood pressure and heart rate. J Appl Physiol 51:1017-1022

43. Mulder AL, Golde JM, Goor AA, Giussani DA, Blanco CE 2000 Developmental changes in plasma catecholamine concentrations during normoxia and acute hypoxia in the chick embryo. J Physiol 527:593-599

44. Mulder AL, van Goor, CA, Giussani DA, Blanco CE 2001 Alpha-adrenergic contribution to the cardiovascular response to acute hypoxemia in the chick embryo. Am J Physiol Regul Integr Comp Physiol 281:R2004-R2010

45. Giussani DA, Spencer JA, Hanson MA 1994 Fetal cardiovascular reflex responses to hypoxaemia. Fetal Matern Med Rev 6:17-37

46. Keller BB, Yoshigi M, Tinney, JP 1997 Ventricular-vascular uncoupling by acute conotruncal occlusion in the stage 21 chick embryo. Am J Physiol 273:H2861-H2866

47. Tobita K, Schroder EA, Tinney JP, Garrison JB, Keller BB 2002 Regional passive ventricular pressure-strain relations during development of altered loads in the chick embryo. Am J Physiol Heart Circ Physiol 282:H2386-H2396

48. Schroder EA, Tobita K, Tinney JP, Keller BB 2002 Microtubule involvement in the adaptation to altered mechanical load in the developing chick myocardium. Circ Res 91:353-359

49. Burggren WW, Fritsche R 1997 Amphibian cardiovascular development. In: Burggren W, Keller BB (eds) Development of Cardiovascular Systems: Molecules to Organisms. Cambridge University Press, New York, pp 166-182

50. Ruijtenbeek K, Kessels LC, De Mey, JG, Blanco CE 2003 Chronic moderate hypoxia and protein malnutrition both induce growth retardation, but have distinct effects on arterial endothelium-dependent reactivity in the chicken embryo. Pediatr Res 53:573-59

51. Krampl ER, Espinoza-Dorado J, Lees CC, Moscoso G, Bland JM, Campbell S 2001 Maternal uterine artery Doppler studies at high altitude and sea level. Ultrasound Obstet Gynecol 18:578-582

52. Sohn SJ, Sarvis BK, Cado D, Winoto A 2002 ERK5 MAPK regulates embryonic angiogenesis and acts as a hypoxia-sensitive repressor of vascular endothelial growth factor expression. J Biol Chem 277:43344-43351

53. Compernolle V, Brusselmans K, Franco D, Moorman A, Dewerchin M, Collen D, Carmeliet P 2003 Cardia bifida, defective heart development and abnormal neural crest migration in embryos lacking hypoxia-inducible factor-1alpha. Cardiovasc Res 60:569-579

54. Sugishita Y, Leifer DW, Agani F, Watanabe M, Fisher SA 2004 Hypoxia-responsive signaling regulates the apoptosis-dependent remodeling of the embryonic avian cardiac outflow tract. Dev Biol 273:285-296

55. Dzialowski EM, von Plettenberg, D, Elmonoufy NA, Burggren WW 2002 Chronic hypoxia alters the physiological and morphological trajectories of developing chicken embryos. Comp Biochem Physiol A Mol Integr Physiol Part A 131:713-724 